\title{
SCREENING AND REFERRAL FOR CHILDREN WITH PHYSICAL DISABILITIES
}

${ }^{1}$ Andrew G. Georgiadis MD, Fellow in Orthopaedic Surgery

${ }^{2}$ Pam Thomason BPhty, MPhysio, Senior Clinical Physiotherapist

${ }^{1,3}$ Kate Willoughby BPhysio, DPhysio, Consultant Physiotherapist, Cerebral Palsy and Hip Surveillance

${ }^{1,2,3,4}$ H. Kerr Graham MD, FRCS (Ed), FRACS Professor of Orthopaedic Surgery

${ }^{1}$ Orthopaedic Department, The Royal Children's Hospital, Flemington Road, Parkville, Victoria 3052

${ }^{2}$ Gait Laboratory, The Royal Children's Hospital, Flemington Road, Parkville, Victoria 3052

${ }^{3}$ Centre of Research Excellence in Cerebral Palsy. Murdoch Childrens Research Institute, Flemington Road, Parkville, Victoria 3052

${ }^{4}$ The University of Melbourne, Grattan Street, Carlton, Victoria 3053

Corresponding Author

Professor H. Kerr Graham

Orthopaedic Department

The Royal Children's Hospital

Flemington Road

Parkville Victoria 3052

E-mail: kerr.graham@rch.org.au

Telephone: 0393455399

Fax:

0393455447

Word Count: 2327

This is the author manuscript accepted for publication and has undergone full peer review but has not been through the copyediting, typesetting, pagination and proofreading process, which may lead to differences between this version and the Version of Record. Please cite this article as doi: $10.1111 /$ jpc.13735

This article is protected by copyright. All rights reserved. 
No conflict of interest declared

This article is protected by copyright. All rights reserved. 
GMFCS E \& $R$ between $6^{\text {th }}$ and $12^{\text {th }}$ birthday:

Descriptors and illustrations

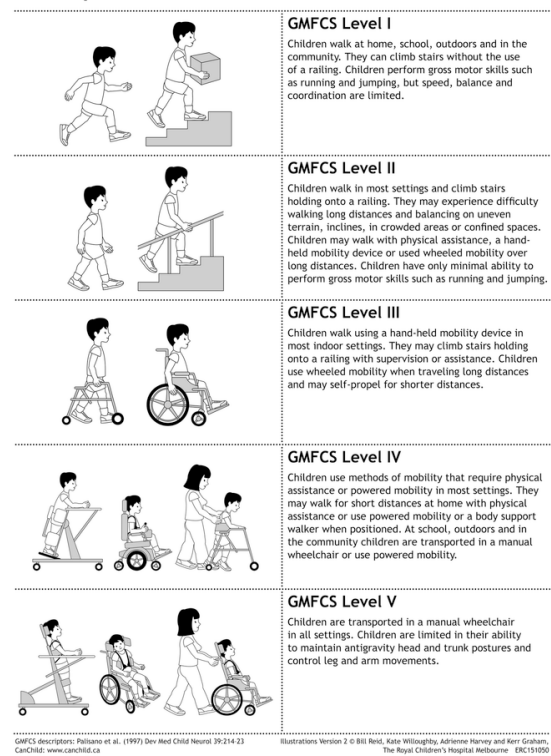

Figure 1 GMFCS 6-12.tif

This article is protected by copyright. All rights reserved. 


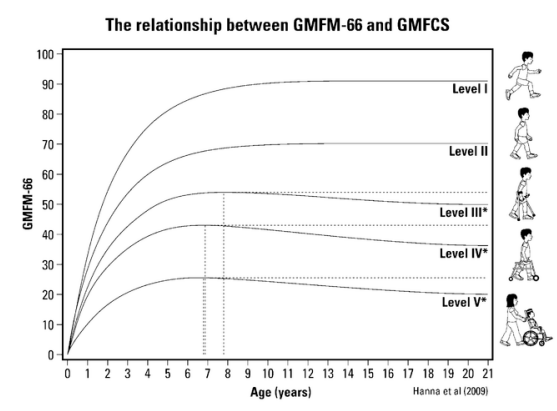

Figure 2 Relation GMFM-66 GMFCS.tif

This article is protected by copyright. All rights reserved. 
CP: Musculoskeletal Management Algorithm

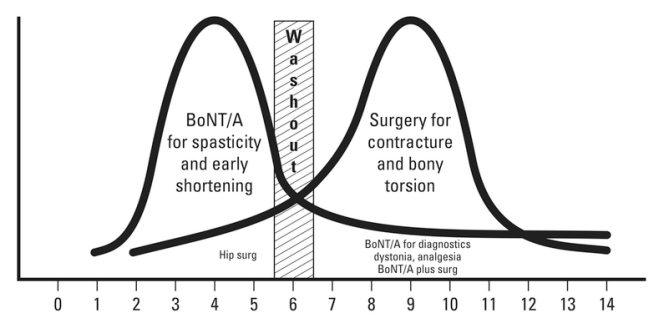

Figure 4 Management algorithm.tif

This article is protected by copyright. All rights reserved. 


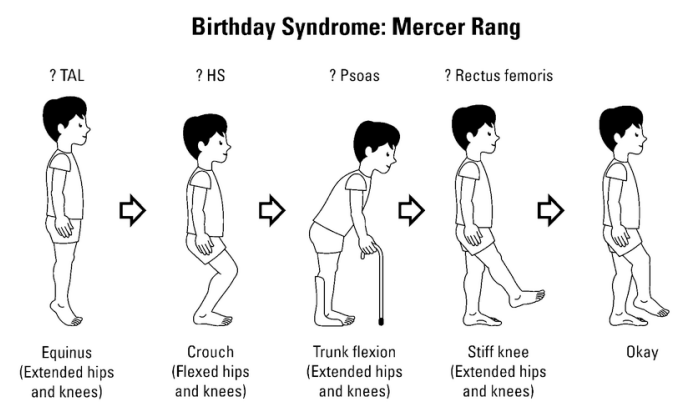

Figure 5 Birthday Syndrome.tif

This article is protected by copyright. All rights reserved. 


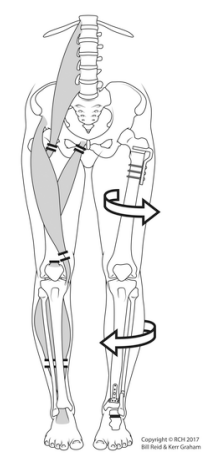

Figure 6 Muscle bone tif

This article is protected by copyright. All rights reserved. 


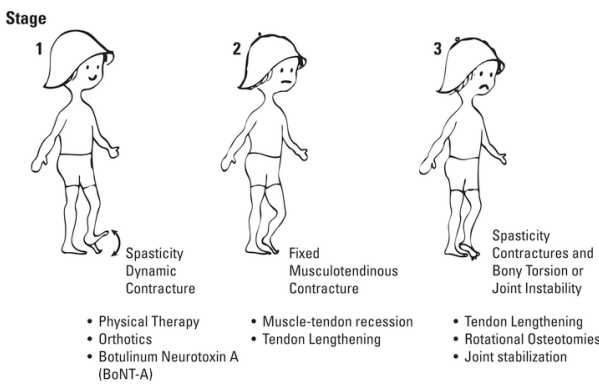

FIGURE 3.tif

This article is protected by copyright. All rights reserved. 


\section{INTRODUCTION}

Cerebral palsy (CP) is the most common cause of physical disability in developed countries and probably in most developing countries, although prevalence rates are less clear in countries without cerebral palsy registers. ${ }^{1}$ The incidence of CP is approximately 2 per 1000 live births with some variation across Australian states and territories as well as with time. ${ }^{2}$ Australia is fortunate to have both state based and a national cerebral palsy register which generates high quality information on the distribution, frequency and severity of $\mathrm{CP}$, the causes and determinants of CP as well as of the effectiveness of prevention strategies. ${ }^{1,2}$ Recent advances in cerebral palsy have led to a revised definition and classification which significantly affect screening and management. ${ }^{3-5}$ The new international definition distinguishes between the static underlying brain lesion and the developmental manifestations which are continually changing and the musculoskeletal manifestations, which are progressive. ${ }^{3}$ A child with delayed milestones and spastic hypertonia may initially present with toe walking because of spasticity. With the passage of time, fixed contractures, long bone torsional deformities and hip displacement may develop. ${ }^{1,3,6,7}$

One of the most significant advances in the field has been the development and widespread utilisation of the Gross Motor Function Classification System (GMFCS) ${ }^{4}$ (Fig.1). The GMFCS is the first and best known of a family of classification systems which also include the Manual Ability Classification System (MACS) and the Communication Function Classification System (CFCS). ${ }^{1}$ The GMFCS is based on data from the Ontario Motor Project in which multiple measurements of gross motor function in children with $\mathrm{CP}$ were used to generate a series of curves describing gross motor function from birth to age 15 years and which can be stratified according to a five level ordinal grading system ${ }^{4,8}$ (Fig. 2). At GMFCS level I, children have mild impairment and are capable of high levels of independent functioning including walking unaided, running and participating in sport. At GMFCS level II, children are capable of independent walking but have a greater degree of restriction in physical activities, especially on uneven surfaces and when participating in sport. At GMFCS level III, children ambulate with an assistive device like crutches or a walking frame. At GMFCS level IV children have head control and sitting balance and may have the ability to stand for transfers but do not have functional walking and are largely dependent on wheeled mobility. ${ }^{1,4}$ At GMFCS level V children lack head control, are dependent on carers for all aspects of their care and are reliant on wheelchair mobility. The GMFCS has been shown to be valid, reliable, stable over time and predictive of long-term gross motor function. ${ }^{1,4} \mathrm{We}$ 
find illustrations of GMFCS and gross motor curves to be essential in outpatient clinics for clear communication with parents and colleagues. The Illustrations for the GMFCS, which were created by Medical Illustrator, Bill Reid at The Royal Children's Hospital in Melbourne, for children age 6-12 and 12-18 are available from the authors, and are also available from the CanChild website: https://www.canchild.ca/en/resources/42-gross-motorfunction-classification-system-expanded-revised-gmfcs-e-r.

From the surgeon's point of view a child's GMFCS classification is highly predictive of musculoskeletal issues like hip displacement, the shape of the proximal femur and scoliosis. ${ }^{1,9-11}$ We consider the GMFCS to be the essential tool for communication about children with $\mathrm{CP}$ as it is the foundation for all meaningful discussions regarding long-term prognosis and management. ${ }^{1,4}$ It should be noted that the GMFCS has only been validated for children with $\mathrm{CP} .{ }^{4}$ It is therefore not recommended that this classification system be used for other physical disabilities. In ambulatory patients, the Functional Mobility Scale (FMS) is used to classify children's functional mobility and is complementary to the GMFCS. The FMS is not cerebral palsy or disease-specific and can be used to describe the mobility and aids required by children with $\mathrm{CP}$ and other diagnoses including myelomeningocele, muscular dystrophy, Rett syndrome (RS) and spinal muscular atrophy (SMA). ${ }^{5}$ The advantage of the FMS is that it allows classification of mobility needs at three different levels, 5 metres representing household ambulation, 50 metres representing ambulation within a confined safe environment, and 500 metres representing community mobility needs. ${ }^{5}$ We recommend the use of the FMS in communicating the mobility needs of children with all physical disabilities. ${ }^{1,5}$

\section{Brain Lesions, Spinal Lesions, Musculoskeletal Deformities and Natural History}

At birth, children with CP and many other physical disabilities do not have contractures, hip displacement or scoliosis. Fixed deformities develop with time and may be the result of functional limitations and growth. ${ }^{6}$ In the past, the positive features of the upper motor neuron syndrome such as spasticity were thought to be the principal agent driving the development of deformity. However, population-based work in Melbourne has showed a linear correlation between the risk of hip displacement and limitations in mobility as described by the GMFCS. ${ }^{9}$ This study also showed that the type of motor disorder (hypotonia, spasticity, dystonia) was not predictive of hip displacement whereas the relationship between hip displacement and GMFCS was essentially linear. Children at 
GMFCS level I had a negligible risk of hip displacement and children at GMFCS level V had a $90 \%$ risk of hip displacement. ${ }^{1,9}$ We therefore think that the aetiology of many musculoskeletal problems in CP is the result of the functional limitation and not spasticity or dystonia. This is also true in such diverse disabilities as SMA and RS. This also explains why interventions to ameliorate spasticity have limited potential in the prevention of secondary musculoskeletal pathology. ${ }^{6,12}$ The natural history and the severity of musculoskeletal deformities seems to be related to limitations in walking more than any other single factor ${ }^{1,6}$.

\section{The Ambulant Child: Screening for Gait Disorders and Contractures}

In children with diplegia, toe walking is common from the time the child pulls to stand. Initially this is caused by spasticity or dystonia and there is no fixed contracture of the gastrocsoleus. ${ }^{1,6}$ At this stage, non-operative management is ideal and usually consists of a combination of injections of Botulinum toxin A (BoNT-A), the use of ankle-foot-orthoses (AFOs) combined with a physiotherapy $\operatorname{program}^{13}$ (Figs. 3 and 4). The effects of BoNT-A on toe walking and overall gait are small but helpful in early childhood. ${ }^{1}$ Because of the rapid acquisition of motor skills in the first five years of life, improvements due to natural history, versus those achieved by injecting BoNT-A or other interventions are difficult to disentangle ${ }^{1}$ (Fig. 2). Nonetheless, early surgery for toe walking is ill advised and now rarely practiced. ${ }^{14}$ Historical studies showed very high rates of overcorrection to crouch gait when surgical lengthening of the gastrocsoleus was performed in isolation in younger children. ${ }^{6,7,14}$ With the passage of time, the majority of ambulant children with CP gradually develop fixed contractures and exhibit torsional deformities resulting in common gait patterns like toe walking and intoeing. ${ }^{7}$ In the past, surgical treatment was based on watching the child walk, a.k.a. "observational gait analysis", a physical examination and a limited surgical approach such as isolated lengthening of the Achilles tendon. ${ }^{14}$ Multiple episodes of surgery were performed throughout early childhood and this approach has been described by Mercer Rang as "The Birthday Syndrome" 7 (Fig. 5). The child spent most birthdays in the first 10 years of life either in hospital, in casts, or in rehabilitation. The current approach is to defer all surgery, except that required for the prevention of hip displacement until the child is at least six years old with the ideal age being probably 8-10 years. ${ }^{7}$ This is the ideal time for surgical intervention, before muscle contractures progress to joint contractures. Muscle contractures are easily managed by muscle-tendon lengthening. Surgery for contractures of the knee in teenagers with severe crouch gait is associated with high rates of surgical 
complications, requires prolonged rehabilitation and is often associated with anxiety and depression. ${ }^{1,6}$

Computerised three dimensional gait analysis is then required to identify all of the factors affecting the child's walking pattern. ${ }^{15}$ Three dimensional gait analysis includes sophisticated recording methods for gait which include Strobe cameras, force plates and dynamic electromyography. ${ }^{1,15}$ In combination with clinical examination and functional scales, a full biomechanical assessment for each child can be profiled. This can be used for surgical planning for an approach known as Single Event Multilevel Surgery (SEMLS) pioneered at The Royal Children's Hospital in Melbourne. ${ }^{1,7,15}$ In this approach, following gait laboratory analysis, a surgical plan consisting of bilateral surgery at hip, knee, and foot and ankle levels is devised for the correction of all fixed deformities in one major operative session, requiring two experienced surgeons and two experienced assistants ${ }^{16}$ (Fig. 6). This is then followed by a short period of below knee plaster casts, the fitting of appropriate orthoses and an intensive rehabilitation program which lasts for approximately one year. ${ }^{17}$ In a randomised clinical trial, this approach has been shown to improve all aspects of gait and functioning in all domains of the World Health Organization International Classification of Functioning (WHO-ICF). ${ }^{16}$ The improvements in gross motor function (GMFM-66) are at best modest and average between $4-5 \%$. The improvements in gait function are more substantial, ranging from $30-50 \%$ using composite gait indices. ${ }^{16}$ Most heartening is the maintenance of these improvements in the majority of children for between 5 and 10 years, comprising childhood, the pubertal growth spurt and into skeletal maturity. ${ }^{18}$ Very long-term multicentre studies are underway confirming the safety and durability of this approach. However, these results are only obtained in centres where children have access to three dimensional gait analysis, an appropriate preparation during the non-operative phase of treatment by specialists in paediatric rehabilitation and when the surgical team has both experience and an appropriate surgical volume of at least 5 and preferably $>10$ children per annum. ${ }^{19}$

\section{Screening for Hip Displacement}

The linear relationship between GMFCS level and hip displacement provided the foundation for the development of hip surveillance guidelines for children with $\mathrm{CP}$ in which a group of Australian researchers has played a distinguished and pivotal role. ${ }^{20,21}$ Over a period of 15 years, a national group of Australian researchers has used emerging studies on the link between GMFCS and hip displacement to develop a series of recommendations for the early 
detection of hip displacement in children with cerebral palsy, permitting more efficient management. ${ }^{20-22}$ From the onset, it was recognised that physical examination is unreliable in detecting early hip displacement and that the basis of surveillance must be periodic anteroposterior radiographs of the hip. ${ }^{21-23}$ The Australian Hip Surveillance Guidelines have been widely disseminated, recently updated and are providing a template for similar guidelines being developed in the UK and in North America by such groups as the American Academy of Cerebral Palsy and Developmental Medicine (AACPDM) and the Pediatric Orthopaedic Society of North America (POSNA). Hip surveillance is now widely practised in most Australian states and territories and, with the development of digital radiology, information can be quickly updated and shared by all involved in the multidisciplinary care of children with CP including physiotherapists, developmental paediatricians, community paediatricians and specialists in paediatric rehabilitation. ${ }^{23}$ The "Australian Hip Surveillance Guidelines for Children with Cerebral Palsy: 2014" are available for download at https://ausacpdm.org.au/professionals/hip-surveillance/australian-hip-surveillanceguidelines/. The purpose of hip surveillance is to permit early detection allowing a wider range of surgical solutions with the long-term aim of prevention of painful hip dislocation and preservation of function..$^{22}$ Population-based studies in Queensland ${ }^{22}$ and long-term population-based studies in Victoria have demonstrated the practicality and effectiveness of this approach. ${ }^{19}$ The link between increasing limitations in walking and increased risk of hip displacement, holds true in both RS and SMA. ${ }^{24}$

\section{Screening for Spinal Deformity and Scoliosis}

More recently, a link between GMFCS and the development of spinal deformity has been identified by researchers in both Australia and Sweden. ${ }^{1,25}$ The link between spinal deformity and GMFCS is similar to the relationship between hip displacement and GMFCS, with some important differences. Small spinal curves are common at all GMFCS levels but only progress to 40 degrees or more, the threshold for surgical intervention, in children who are non-ambulant i.e. GMFCS IV and V. The next step in the evolution of screening approaches will be to formalise screening for spinal deformity in the same manner that has been so successful in screening for hip displacement. ${ }^{1}$ The link between limitations in walking and both the risk and the rate of progression of scoliosis also holds true in SMA and RS. ${ }^{26}$ With rare disorders such as Rett syndrome it is also important (and humbling!) to remember that parents may know more about their child's condition than their medical specialists. An outstanding example of a collaboration between parents, clinicians and researchers to develop 
comprehensive and useful information is "Scoliosis in Rett Syndrome" available at https://rett.telethonkids.org.au/globalassets/subsite-media/subsite-documents/rettsyndrome/scoliosis_booklet.pdf

Although this publication was international in development, it was heavily influenced by Australian researchers from both Perth and Melbourne.

\section{Conclusion}

Although the majority of surgical procedures for hip stabilisation and gait improvement in children with physical disabilities are relatively simple, the timing of surgery, the combinations of procedures required, the dose of surgery and the rehabilitation is exceedingly complex. ${ }^{16-19}$ For example, a recent long-term follow-up study has demonstrated that in a high volume centre such as The Royal Children's Hospital, the success rate of preventive and reconstructive surgery for the hip at mean 19-year follow-up was $90 \%$. In contrast, at nonspecialist centres the failure rate was $71 \% .^{19}$ The issue of surgical volume is also supported by a large study of proximal femoral varus derotational osteotomy of the femur for children with cerebral palsy, from Boston Children's Hospital. Good outcomes were associated with older age at surgery, higher GMFCS level and high surgeon volume. ${ }^{27}$ It is not only surgical volume but the degree of a surgeon's specialisation in a specific subspecialty area that is important in determining outcomes. ${ }^{28}$

The implications of this are clear. Orthopaedic surgery has only a small role to play in the overall management of children with physical disabilities. However, when it is required it should be conducted at the right time and restricted to high volume centres with access to all of the supporting technology, including three dimensional imaging, three dimensional gait analysis and both inpatient and outpatient rehabilitation. ${ }^{1,7,16,18,19,27}$ 


\section{REFERENCES}

1. Graham HK, Rosenbaum P, Paneth N, et al. Cerebral Palsy. Nature Reviews Disease Primers 2016;2:15082

2. Report of the Australian Cerebral Palsy Register Report. Birth Years 1993-2009, September 2016.

3. Rosenbaum P, Paneth N, Leviton A, Goldstein M, Bax M, Damiano D et al. A report; the definition and classification of cerebral palsy April 2006. Dev Med Child Neurol Suppl 2007 Feb;109:8-14

4. Palisano R, Rosenbaum P, Walter S, Russell D, Wood E, Galuppi B. Development and reliability of a system to classify gross motor function in children with cerebral palsy. Dev Med Child Neurol 1997;39(4):214-223.

5. Graham HK, Harvey A, Rodda J et al. The functional mobility scale. J Pediatr Orthop 2004;24:514-20.

6. Graham HK. Mechanisms of deformity. In: Scrutton D, Damiano D, Mayston M eds. Management of the motor disorders of children with cerebral palsy. Chapter $8,2^{\text {nd }} \mathrm{ed}$. Clinics Dev Med No 161. London UK. MacKeith Press 2004;105-29.

7. Graham HK, Thomason P, Novacheck TF. Cerebral Palsy. In: Lovell and Winter's Pediatric Orthopaedics. Chapter 14, p484-554. Eds. Weinstein SL, Flynn JM. Wolters Kluwer Philadelphia 2014. Seventh Edition. ISBN 978-1-60547-814-2.

8. Rosenbaum PL, Walter SD, Hanna SF et al. Prognosis for gross motor function in cerebral palsy, creation of motor development curves. JAMA 2002;288:1357-63.

9. Soo B, Howard JJ, Boyd RN, Reid SM, Lanigan A, Wolfe R, Reddihough D, Graham HK. Hip displacement in cerebral palsy. J Bone Joint Surg 2006;88-A:121-9.

10. Connelly A, Flett P, Graham HK, Oates J. Hip surveillance in Tasmanian children with cerebral palsy. J Pediatr Child Health 2009;45(7-8):437-43.

11. Robin J, Graham HK, Selber P, Dobson F, Smith K, Baker R. Proximal femoral geometry in cerebral palsy: a population-based cross-sectional study. J Bone Joint Surg 2008;90-B:1372-9.

12. Willoughby K, Ang SG, Thomason P, Graham HK. The impact of Botulinum toxin A and abduction bracing on long-term hip development in children with cerebral palsy. Dev Med Child Neurol 2012;54:743-7. 
13. Hastings-Ison T, Blackburn C, Rawicki B, Fahey M, Simpson P, Baker R, Graham HK. Injection frequency of Botulinum toxin A for spastic equinus - A randomized clinical trial. Dev Med Child Neurol 2016;58:750-7.

14. Borton DC, Walker K, Pirpiris M, Nattrass GR, Graham HK. Isolated calf lengthening in cerebral palsy. Outcome analysis of risk factors. J Bone Joint Surg 2001;83-B:36470.

15. Davids JR, Ounpuu S, DeLuca PA, et al. Optimization of walking ability of children with cerebral palsy. J Bone Joint Surg 2003;85-A:2224-34.

16. Thomason P, Baker R, Dodd K, Taylor N, Selber P, Wolfe R, Graham HK. SingleEvent Multilevel Surgery in children with spastic diplegia. A pilot randomized controlled trial. J Bone Joint Surg 2011;93-A:451-60.

17. Thomason P, Graham HK. Rehabilitation of children with cerebral palsy after Single Event Multilevel Surgery. In: Rehabilitation in Movement Disorders. Chapter 18, p20316. Eds Iansek R, Morris ME. Cambridge University Press 2013. ISBN:978-1-10701400-8.

18. Thomason P, Selber P, Graham HK. Single Event Multilevel Surgery in children with bilateral spastic cerebral palsy: A 5 year prospective study. Gait \& Posture 2013;37:238.

19. Wawrzuta J, Willoughby KL, Molesworth C, Ang SG, Shore BJ, Thomason P et al. Hip health at skeletal maturity: a population-based study of young adults with cerebral palsy. Dev Med Child Neurol 2016;58:1273-80.

20. Wynter M, Gibson N, Kentish M, Love S, Thomason P, Graham HK. The development of Australian Standards of Care for Hip Surveillance in Children with Cerebral Palsy: How did we reach consensus? J Pediatr Rehab Med 2011;4:1-12.

21. Wynter M, Gibson N, Willoughby KL, Love S, Kentish M, Thomason P et al. Australian hip surveillance guidelines for children with cerebral palsy: 5-year review. Dev Med Child Neurol 2015;57:808-20

22. Dobson F, Boyd RN, Parrott J, Nattrass GR, Graham HK. Hip surveillance in children with cerebral palsy. Impact on the surgical management of spastic hip disease. $J$ Bone Joint Surg 2002;84-B:72-6

23. Kentish M, Wynter M, Snape N, Boyd R. Five-year outcome of state-wide hip surveillance of children and adolescents with cerebral palsy. J Pediatr Rehabil Med 2011;4:205-17. 
24. Tay G, Graham H, Graham HK, Leonard H, Reddihough D, Baikie G. Hip displacement and scoliosis in Rett syndrome - screening is required. Dev Med Child Neurol 2010;52:93-8

25. Persson-Bunke M, Hagglund G, Lauge-Pedersen H, Wagner P, Westbom L. Scoliosis in a total population of children with cerebral palsy. Spine 2012;37:E708-13.

26. Downs J, Royce DP Jr, Torode IP, Ellaway C, Baikie G, Larsson E-L, McKenzie A and Leonard H on behalf of the Australian Rett Syndrome Study, Scoliosis in Rett Syndrome: A collaboration between parents, clinicians and researchers. Perth, Telethon Institute for Child Health Research, 2009.

https://rett.telethonkids.org.au/globalassets/subsite-media/subsite-documents/rettsyndrome/scoliosis_booklet.pdf

27. Shore BJ, Zurakowski D, Dufreny C, Powell D, Matheney TH, Snyder BD. Proximal femoral varus derotation osteotomy in children with cerebral palsy. J Bone Joint Surg Am 2015;97:2024-31.

28. Sahni NR, Dalton M, Cutler DM, Birkmeyer JD, Chandra A. Surgeon specialization and operative mortality in United States: retrospective analysis. BMJ 2016;354:i3571.

This article is protected by copyright. All rights reserved. 


\section{University Library}

\section{- M M N E R VA A gateway to Melbourne's research publications}

Minerva Access is the Institutional Repository of The University of Melbourne

Author/s:

Georgiadis, AG;Thomason, P;Willoughby, K;Graham, HK

Title:

Screening and referral for children with physical disabilities

Date:

2017-11-01

Citation:

Georgiadis, A. G., Thomason, P., Willoughby, K. \& Graham, H. K. (2017). Screening and referral for children with physical disabilities. JOURNAL OF PAEDIATRICS AND CHILD HEALTH, 53 (11), pp.1111-1117. https://doi.org/10.1111/jpc. 13735.

Persistent Link:

http://hdl.handle.net/11343/293742 